Journal of

Language and

JLD (PRINT) ISSN 2397-2637

Discrimination

JLD (ONLINE) ISSN 2397-2645

Review

\title{
Corpus, Discourse and Mental Health \\ By D. Hunt and G. Brookes (2020) \\ London: Bloomsbury, 288pp.
}

\author{
Reviewed by Dr Simone C. Bacchini
}

'Corpus, Discourse and Mental Health' presents an analysis of the linguistic practices of members of various online linguistic communities for people living with a number of conditions affecting mental health. Specifically, these conditions are anorexia nervosa, diabulimia, and depression (often in combination). The study uses a corpus linguistics-based discourse analysis and will be of considerable interest to anyone who wishes to deepen their understanding of mental health, online communities and online communication, patient-centred care and the patient perspective, as well as anyone interested in the lived experience of those who face mental health problems. To quote the authors, the 'book is about the language that people use to talk about mental distress' (1).

Most people working in the social sciences will be familiar with notions such as 'discourse' and 'discourse analysis'. Among many (although by no means all of them), the term is understood in the Foucauldian sense of the entirety of texts and linguistic practices of a particular field, like psychiatry. This is often referred to as 'Big D Discourse or Discourses' (Gee and Gee 2007). For linguists, however, 'discourse' has a more specific definition, broadly referring to language over and above the sentence, 'connected stretches of language that make sense, like conversations, stories, reports, arguments, essays' (Gee and Gee 2007:142). As Gee and Gee note, small-D discourse is always part of big-D discourse; both the former and the latter can be, and indeed are, written and spoken.

Corpus-based research, the methodology used by this volume, is a relatively recent approach, made possible by developments in computer

Affiliation

The British Library, London, UK

email: simone.bacchini@bl.uk 
science. It makes use of large collections of texts (corpora), born as written pieces or transcribed from recorded oral interactions and monologues. These texts are then analysed with the help of specific software and through the expertise of researchers.

The volume comprises eight chapters. Chapter 1 introduces the reader to the study and its theoretical and cultural underpinnings. By way of background, the authors present a useful discussion of mental health and the medicalisation of distress. They make clear (4) that they espouse a view that 'mental disorders are socially and discursively constructed. In so doing, they give the reader a user-friendly overview of the two most important epistemological points of view in current debates on psychopathology: namely, 'medical naturalism' and 'social constructionism'. Subsequently, they offer a clear overview of what is meant by 'discourse' and of various approaches to studying it, beginning with corpus linguistics. This section is very clear and, as well as grounding the work, allows the reader, who may not be familiar with either discourse or corpus linguistics (or both), to find a sure footing; this, in turn, will allow him or her to easily navigate the rest of the book.

The reader receives a further orientation in the second chapter. Here the authors provide a more detailed discussion of the particular mental conditions that their study is concerned with: anorexia, depression, and diabulimia. This is especially useful because if, arguably, the first two are rather well known (albeit still often misunderstood), the last one isn't (at least to this reviewer). Diabulimia is an eating disorder in which individuals with Type 1 diabetes, who are insulin dependent, restrict their insulin in order to shed calories and control their body weight' (50). However, as the authors point out, the understanding of these three conditions is disputed. Crucially, as the authors show, different understanding, both from the professionals' and the sufferers' side, are linguistically and discursively construed and presented.

In Chapter 3, the reader is introduced to the nature of the study's data and the methodology used. It opens with a discussion of online peer-topeer health support groups. As the authors explain, these are:

'online, computer-mediated platform $[\mathrm{s}]$ which offer $[\ldots]$ users the chance to interact with large numbers of (usually) unknown others for the purpose of sharing ideas, telling stories and seeking and providing support about a range of topics.' (59-60)

The numbers of such fora have grown exponentially, since the birth of the internet. The authors illustrate well why they are important, for example, because of the possibility they afford their users to narrate their viewpoints

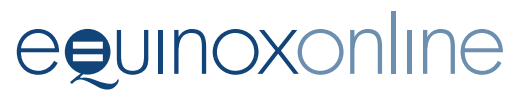


without mediation and to connect with others in the same or a similar situation. This is particularly important because in the case of mental health there is still a considerable amount of stigma. Being able to discuss such matters anonymously (if this is how users choose to interact), without faceto-face interaction, is often felt as liberating and empowering. However, such platforms have also attracted criticism. One reason for this is the lack of control of quality over content; this may result in inaccurate, even harmful information being circulated. The remainder of the chapter is dedicated to a more detailed discussion of the data and the methodology used.

Chapters 4-6 relate the analysis. In Chapter 4, the reader finds out how members of one forum discursively construct anorexia, and how - in relation to it - their identities are negotiated and constructed. It is very interesting to notice how, through the data, the authors are able to show how each posted message fulfils different interactional goals, such as affirming one's autonomy by, for example, distancing oneself from the medical view of the disorder. Another interesting finding is that in the users' posts, anorexia is often personified and construed as an autonomous entity. The effect is that users are able to distance themselves from the disorder and to mitigate their responsibility in the face of a condition that is often stigmatised.

The discourse(s) used by participants in the fora to discuss depression, as well as that of the closely linked ones of antidepressants and self-harming behaviour, are the subject of Chapter 5 . The authors conclude that, rather than one single discourse of depression, several, at times contradictory ones, exist. This is perhaps unsurprising, given that, like other illnesses, depression is experienced individually by different people. From the analysis, it is clear that depression is never static, and nor is how individuals 'interact' with it. For example, the agency that individual experience vis-àvis depression is fluid and the product of ongoing negotiations with society, the medical profession, and the condition itself.

Chapter 6 considers diabulimia, and the messages posted about it, on support platforms for people with diabetes. The chapter is revealing in the way in which it sheds light on the interconnectedness of multiple pathologies, as well as on self-perception in relation to body image. Thus, diabulimia is revealed, in contrast to the two other conditions, as a 'dual pathology'. This can be seen as a complicating factor, in that the requirements to combat bulimia and diabetes can become conflictual and the individual has to navigate and negotiate opposing pressures.

Chapter 7 discusses the main components of the previous chapters. It highlights common themes and differences, both at the micro and macro levels. The chapter discusses how individuals can use online support fora 
to alleviate, by sharing, the stigma of living with their conditions and find support.

Chapter 8 brings the study to a conclusion, very usefully discussing the implications for both patients and the medical profession. Arguably, these conclusions can also be of use to family members, friends, and anyone with an interest in mental health issues.

Corpus, Discourse and Mental Health is a very good example of how linguistics, and in particular corpus linguistics, can assist in giving a better, evidence-based understanding of the lived experience of mental health patients. This is a well-researched, excellently presented study. As such, it can inspire anyone with an interest in mental health to conduct their own research. This might not be possible at the same scale, yet, because of the clarity with which the authors present their approach, it can certainly help in using language as a point of entry to the experience of mental distress.

The authors are to be commended for the way in which they communicate across disciplines and to the wider public. After reading this book, readers will find themselves better equipped to understand depression, anorexia nervosa, and diabulimia. They will also acquire a better understanding of discourse studies, corpus linguistics, and stigma in the experience of mental illness. Crucially, they will find that attention to the language used by people with any kind of illness always pays.

\section{Reference}

Gee, J. and Gee, J. P. (2007) Social Linguistics and Literacies: Ideology in Discourses. Abingdon: Taylor \& Francis. https://doi.org/10.4324/9780203944806 